\title{
Alpine Newts (Ichthyosaura alpestris) Avoid Habitats Previously Used by Parasite-Exposed Conspecifics
}

\author{
David R. Daversa ${ }^{1,2,3,4 *}$, Andrea Manica ${ }^{2}$, Héctor Bintanel Cenis ${ }^{5}$, Pilar Lopez ${ }^{6}$, \\ Trenton W. J. Garner ${ }^{3}$ and Jaime Bosch ${ }^{6,7,8}$ \\ ${ }^{1}$ La Kretz Center for California Conservation Science, Institute for the Environment and Sustainability, University of California, \\ Los Angeles, Los Angeles, CA, United States, ${ }^{2}$ Department of Zoology, University of Cambridge, Cambridge, \\ United Kingdom, ${ }^{3}$ Institute of Zoology, Zoological Society of London, London, United Kingdom, ${ }^{4}$ Institute of Integrative \\ Biology, University of Liverpool, Liverpool, United Kingdom, ${ }^{5}$ Athmos Sustainability, Zaragoza, Spain, ${ }^{6}$ Museo Nacional \\ de Ciencias Naturales, CSIC, Madrid, Spain, ${ }^{7}$ Research Unit of Biodiversity (CSIC, UO, PA), Gonzalo Gutiérrez Quirós s/n, \\ University of Oviedo, Mieres, Spain, ${ }^{8}$ Centro de Investigación, Seguimiento y Evaluación, Parque Nacional de la Sierra \\ de Guadarrama, Rascafría, Spain
}

OPEN ACCESS

Edited by:

Julia Buck,

University of North Carolina

Wilmington, United States

Reviewed by:

Collin James Horn,

University of Alberta, Canada

Thomas Raffel,

Oakland University, United States

*Correspondence:

David R. Daversa

ddaversa@ioes.ucla.edu

Specialty section:

This article was submitted to

Behavioral and Evolutionary Ecology,

a section of the journa

Frontiers in Ecology and Evolution

Received: 30 November 2020

Accepted: 05 February 2021

Published: 11 March 2021

Citation:

Daversa DR, Manica A, Bintanel Cenis H, Lopez P,

Garner TWJ and Bosch J (2021)

Alpine Newts (Ichthyosaura alpestris) Avoid Habitats Previously Used by

Parasite-Exposed Conspecifics.

Front. Ecol. Evol. 9:636099.

doi: 10.3389/fevo.2021.636099
Many organisms avoid habitats posing risks of parasitism. Parasites are not generally conspicuous, however, which raises the question of what cues individuals use to detect parasitism risk. Here, we provide evidence in alpine newts (Ichthyosaura alpestris) that non-visual cues from parasite-exposed conspecifics inform habitat avoidance. Alpine newts breed in aquatic habitats and occasionally move among adjacent terrestrial habitat during breeding seasons. We completed experiments with newts whereby individuals had access to both habitats, and the aquatic habitats varied in prior occupancy by conspecifics with different histories of exposure to the parasitic skin fungus, Batrachochytrium dendrobatidis $(B d)$. Continuous filming of newt activity for 2 days provided little evidence that prior use of aquatic habitats by conspecifics, regardless of their $\mathrm{Bd}$ exposure history, immediately influenced newt habitat use. However, newts that encountered aquatic habitats used specifically by $B d$-exposed conspecifics on day 1 spent less time aquatic on day 2, whereas other newts did not alter habitat use. Responses could have been elicited by cues generated by $B d$ stages on the conspecifics or, perhaps more likely, cues emitted by the conspecifics themselves. In either case, these observations suggest that newts use non-visual cues sourced from exposed conspecifics to detect $B d$ risk and that those cues cause newts to avoid aquatic habitats. $B d$ may therefore influence host behavior in early phases of interactions, and possibly before any contact with infectious stages is made, creating potential for non-consumptive effects.

Keywords: infection risk, habitat use, non-lethal effects, anti-parasite behavior, disease ecology, nonconsumptive effects

\section{INTRODUCTION}

Avoiding habitats containing parasites poses clear benefits. Parasitic infections can be detrimental to individual health and fitness, and in some cases, lead to population collapses (Bosch et al., 2001; Briggs et al., 2010). Free-living organisms can minimize the likelihood of being parasitized by reducing time in habitats posing a risk of infection (Hutchings et al., 2001; Koprivnikar and Penalva, 2015; Daversa et al., 2018a; Mierzejewski et al., 2019). Epidemiologically, 
this behavior reduces rates of contact with infectious parasite stages, an essential ingredient for infection (Anderson and May, 1981). Similar to predator avoidance, parasite avoidance can affect higher-order ecological processes, exemplified by trophic cascades that restructure entire ecosystems (Buck and Ripple, 2017; Buck et al., 2018). Unlike most predators, however, infective parasite stages are in most cases too small relative to their hosts to visually detect, which raises the question of what cues hosts use to avoid habitats posing a risk of infection.

Many cues that inform decision-making are non-visual and come from conspecifics (Chivers et al., 1999; Jacobsen and Stabell, 2004; Plenderleith et al., 2005). Non-visual chemical cues from conspecifics have known roles in mate choice (Plenderleith et al., 2005; Martín and López, 2006) and predator avoidance (Kats and Dill, 1998), and there is evidence in aquatic organisms that parasite infections alter conspecific chemical cues in ways that elicit avoidance behaviors, such as erratic movement and spatial distancing (Poulin et al., 1999; Behringer et al., 2018; Stephenson et al., 2018). Infected conspecifics may also emit cues generated by the parasite that other hosts conceivably detect. Even in the absence of infection, exposure to parasites can affect how conspecific cues are emitted and interpreted (Folstad et al., 1994; Behringer et al., 2018). For example, parasite exposure alters the development of sexual cues, such as attractive odors (Kavaliers et al., 2003, 2004) and bright coloration (Folstad et al., 1994) that can alter mating decisions. The impacts of parasite exposure on host communication provides reason to predict that non-visual cues sourced from parasite-exposed conspecifics drive hosts to reduce use of habitats where the cues are present. This prediction has received little formal testing.

In this study, we tested whether non-visual cues of the parasitic chytrid fungus, Batrachochytrium dendrobatidis ( $B d)$, originating from $B d$-exposed conspecifics elicit changes in aquatic habitat use in female alpine newts (Ichthyosaura alpestris). Alpine newts are prolonged breeders that require extended periods courting and egg-laying in fully aquatic habitats (i.e., lakes and ponds) where $B d$ thrives. $B d$ infects many species of amphibians via microscopic zoospores that are free-living and aquatic (Piotrowski et al., 2004). Infections from $B d$ can cause the disease chytridiomycosis, which is associated with mass mortalities in host populations worldwide (Scheele et al., 2019; Fisher and Garner, 2020). Alpine newts can develop symptomatic disease after contracting infections, but in many cases remain asymptomatic (Miaud et al., 2016; Daversa et al., 2018a). Our previous work suggests that the dynamic nature of newt habitat use may be one explanation for this lack of disease (Daversa et al., 2018a). Alpine newts occasionally move among adjacent terrestrial habitat during breeding seasons (Weddeling et al., 2004; Kopecky et al., 2010; Daversa et al., 2018a). We showed that use of terrestrial habitats by male newts lowers risk of $B d$ infection by reducing both the frequency of exposure to $B d$ zoospores and the growth of $B d$ on infected hosts (Daversa et al., 2018a). Further, male newts spent more time terrestrially after contracting $B d$ infections, especially when infection levels were elevated (Daversa et al., 2018a), illustrating how infection with $B d$ impacts male newt behavior. Here, we built on this work to examine the impact of $B d$ on habitat use of female newts and to test the hypothesis that non-visual cues of $B d$ coming from exposed conspecifics elicit similar increases in terrestrial habitat use.

\section{MATERIALS AND METHODS}

Alpine newts are widely distributed in Europe. We studied newts occupying alpine ponds in Central Spain (Guadarrama National Park, $40.85023 \mathrm{~N},-3.95442 \mathrm{~W}$ ) where they were introduced in the 1980 's. Bd was first detected at the sites in midwife toads (Alytes obstetricans) in the late 1990's (Bosch et al., 2001). Newts test positive for $B d$ infections at the sites, but evidence suggests that newts here do not develop chytridiomycosis, and population declines have not been observed (Bosch et al., 2018; Daversa et al., 2018a). Nevertheless, experimental $B d$ exposures in adult alpine newts can cause infection-induced mortality (Miaud et al., 2016). Infections from $B d$ can therefore be costly to newts.

We designed and executed a controlled experiment with female newts to test hypotheses for the role of conspecific cues and $B d$ on newt habitat use:

- Null Hypothesis: Previous use of water by conspecifics, regardless of their recent history of exposure to $B d$, will not affect the time that newts spend in aquatic habitats.

- Alternative Hypothesis 1: Newts will reduce time in aquatic habitats when the water was previously used by conspecifics generally, irrespective of the $B d$ exposure history of the conspecifics.

- Alternative hypothesis 2: Newts will reduce use of aquatic habitats when the water was previously used specifically by conspecifics recently exposed to $B d$.

We chose to use female newts as experimental subjects to complement our previous experiments with male newts (Daversa et al., 2018a). We ran the experiment for 2 days during late stages of the alpine newt breeding season (August, 2014).

We captured adult male and female newts from a cluster of ponds in Guadarrama National Park and transported them in coolers to "El Ventorrillo," a biological station located apx. 3 miles away. At the station we housed newts in groups, separated by sex and pond of capture, in $20 \mathrm{~L}$ plastic containers containing aged and $B d$-free spring water. To ensure that all newts started the experiment uninfected, we bathed newts with an antifungal solution $(100 \mu \mathrm{L}$ itraconazole/1 L) for $5 \mathrm{~min}$ per day for 4 days (Garner et al., 2009; Daversa et al., 2018a). We confirmed infection-free status of all newts through standard molecular diagnostics and with appropriate positive and negative controls (Boyle et al., 2004; Hyatt et al., 2007; Daversa et al., 2018a). Two days prior to the experiment, we transitioned all females to terrariums with saturated mossy substrate to acclimate them to terrestrial conditions while limiting the likelihood of them changing to a terrestrial phase (Kristín and Gvoždík, 2014).

We generated conspecific cues of $B d$ from male newts because only enough females were collected to use as main experimental subjects. We exposed males individually to $B d(1.5 \mathrm{~L}$ plastic containers that contained $0.4 \mathrm{~L}$ water) after randomly assigning sixty male newts to either a $B d$ exposure group $(N=30)$ or a control group $(N=30)$. To generate infections, we used a $B d$ 
isolate (ID: Pen_Ss9.2 stored in the Imperial Culture Collection, Imperial College London) that was recently isolated from an infected larval fire salamander (Salamandra salamandra) in Guadarrama, the same site in which newts were captured. For males in the treatment group, we dosed containers once per day with an inoculate containing $2.0 \times 10^{6}-4.0 \times 10^{6}$ active $B d$ zoospores and repeated the process for 5 days. For males in the control group we administered a daily dose of sterile liquid media following the same protocol. Twenty-four hours following the final exposure we began cohousing males in large plastic tubs filled with aged Bd-free spring water in groups of six unexposed males (unexposed group) or in groups of three unexposed newts and three exposed newts (exposed group). We used water from these large plastic tubs for use in the experiment, as opposed to the water used for exposures, to ensure that water did not contain residual $B d$ zoospores or media remaining from our inoculates. Any $B d$ zoospores in the experimental water would have been those shed by exposed males that contracted infections.

For the experiment we rotated eighteen females through a series of $2 \mathrm{~L}$ containers that contained equal parts terrestrial and aquatic habitat. The container sides were opaque and prevented visual cues from being transmitted across replicates. Lids were clear, vented plastic which allowed filming while preventing escapes. We used moistened sphagnum moss overlain on a bed of pebbles as terrestrial habitat. The aquatic portion of the containers contained water from one of three sources to mimic different conspecific cues: (a) uninfected and unused aged tap water used for a control $(N=6)$, (b) water taken from a tank housing conspecifics that were not recently exposed to $B d(N=6)$, and (c) water taken from a tank housing conspecifics that were exposed to $B d$ within 14 days of the experiment $(N=6)$. We fully randomized the layout of containers. The experiment began when we introduced newts at random into the terrestrial side of the containers. We kept all newts in the containers for $24 \mathrm{~h}$ (day 1), after which we moved each female into the terrestrial side of the adjacent container and kept them there for another $24 \mathrm{~h}$ (day 2). Newts therefore experienced conditions from two different tanks over the course of 2-day experiment.

To quantify habitat use over the $48 \mathrm{~h}$ experimental period, we digitally recorded female newts using two webcams (Logitech C310, Newark, CA, United States) positioned above the array of eighteen containers. The webcams were wired to a remote laptop (Dell Inspiron 350) and scheduled to automatically capture one image per minute from 9:00 to 21:00 h using ispy webcam software $^{1}$. Experiment procedures and animal collections were approved by the Consejería de Medio Ambiente of Madrid, Spain (permit reference: 10/130923.9/14) and carried out in accordance with approved guidelines.

From the images we classified the state of females as either aquatic (fully or partially in aquatic habitat) or terrestrial (completely out of aquatic habitat) on a per-minute basis. We considered occupation of the container walls as being terrestrial. We calculated the following variables from these data as measures of daily habitat use: (a) the time of first entry into aquatic habitat (i.e., the chronological sequence number when female state first

${ }^{1}$ www.ispyconnect.com changed from terrestrial to aquatic), (b) the proportion of time that females occupied aquatic habitat (i.e., the number of images for which female state was aquatic divided by the of total number of images), (c) the total number of transitions between the two habitats, and (d) the mean length of stay in aquatic habitat before moving back on land.

We performed two sets of analyses. For both analyses, we analyzed day 1 and day 2 data separately because newts experienced distinct conditions each day. Further, we did not have the power to run single models that accounted for interactions with experimental day. First, we carried out a 'timeto-event' analysis (i.e., survival analysis) to determine whether previous use of water by conspecifics influenced how quickly newts first entered the aquatic habitat. The response variables comprised (a) the image sequence number when newts were first shown in aquatic habitat and (b) an event status that indicated whether or not newts ever entered the aquatic habitat. We ran Cox proportional hazard models that incorporated the following fixed effects: the presence of cues from conspecifics in general $(0=$ not present, $1=$ present $)$ and the presence of cues from $B d$ exposed conspecifics in particular $(0=$ not present, $1=$ present $)$, such that:

Day 1 time to entry all conspecific cues (day 1$)+$ Bd-exposed conspecific cues (day 1).

For the model of day 2 activity, we included the cues encountered on both days as fixed effects, to assess whether aquatic habitat experienced on day 1 had a delayed effect on time to entry into aquatic habitat on day 2, such that:

Day 2 time to entry all conspecific cues (day 2) + Bd-exposed conspecific cues $($ day 2$)+$ all conspecific cues $($ day 1$)+B d$-exposed conspecific cues (day 1).

To assess how well the fixed effects predicted time to first entry into aquatic habitat, we compared models with and without each fixed effect, using likelihood ratio tests as a measure of significance.

For our second analysis we ran generalized linear models (GLMs) to test the influence of cues in aquatic habitats on the three other habitat use variables. In the models for the proportion of time that females occupied aquatic habitat, we used the arcsinetransformed value as the dependent variable and a Gaussian error structure. In the models for habitat transitioning, we used the total number of transitions as the dependent variable and a negative binomial error structure to account for overdispersion of the count data. In the model for the average length of stay in aquatic habitat, we used the log-transformed value to normalize the distribution of the data. We included the same fixed effects in the day 1 and Day 2 models as described for the time-toevent analysis (Day 1: presence of cues from any conspecifics, presence of cues from $B d$-exposed conspecifics; Day 2 presence of cues from any conspecifics on Day 1 and Day 2, presence of cues from $B d$-exposed conspecifics on Day 1 and Day 2). In both the day 1 and day 2 analyses we generated sets of candidate models based on different combinations of the fixed effects of the full model (Johnson and Omland, 2004). We ranked the performance of model subsets using Akaike's Information Criterion with 

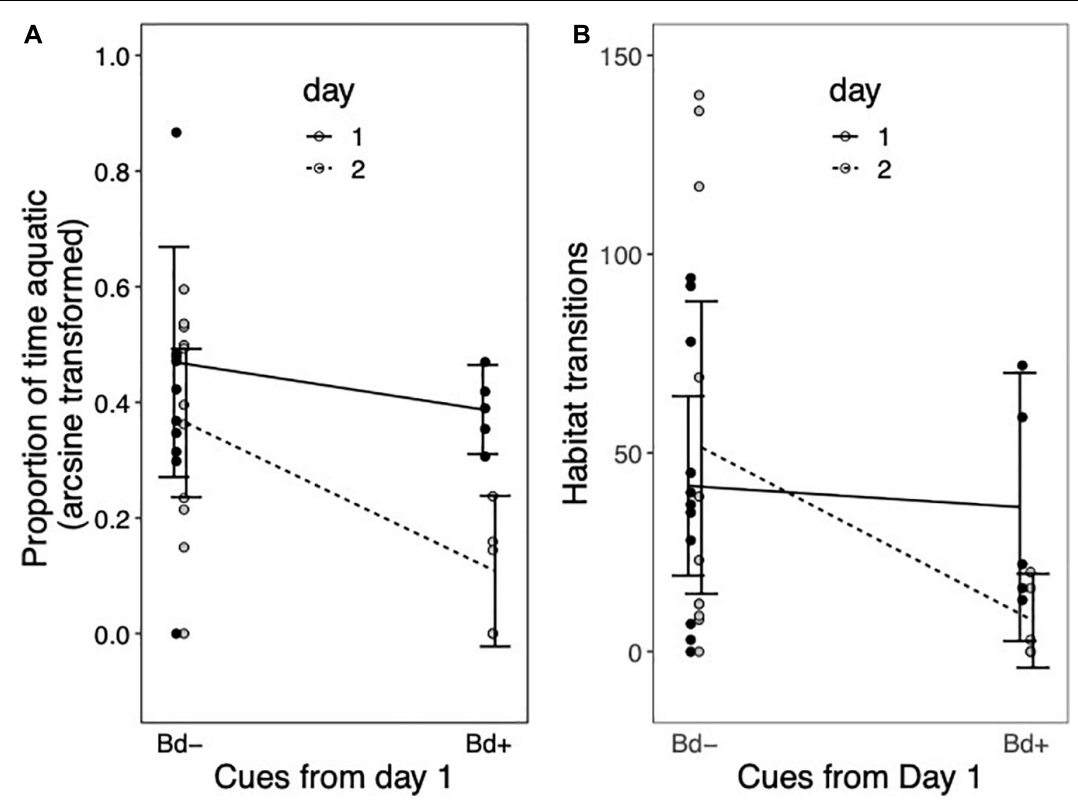

FIGURE 1 | Effects of Day 1 cues on immediate and future aquatic activity. (A) The proportion of total time that females spent aquatically (arc-sine transformed) and (B) the number of transitions between aquatic and terrestrial habitats on day 1 (black points, solid line) and day 2 (gray points and dashed line) is shown. Newts are classified according to whether they experienced water on Day 1 that was previously used by $B d$-exposed conspecifics (Bd+) or water with no cues of $B d$ (Bd-).

Lines are drawn between the mean value for each class, and error bars denote the 95\% confidence intervals.

small sample size correction (AICc) and considered models that ranked within 2 AICc values of the best performing model to be informative (Burnham and Anderson, 2002). We discounted models in which better performing models were nested to avoid the inclusion of uninformative parameters (Arnold, 2010). We performed all analyses in $\mathrm{R}$ ( $\mathrm{R}$ Core Team, 2019). We used the "survival" package (Therneau, 2015) to run the Cox proportional hazard models, "stats" (R Core Team, 2019) and "MASS" (Venables and Ripley, 2002) packages to fit GLMs and the dredge function in the "MuMIn" (Bartoñ, 2019) package for model ranking.

\section{RESULTS}

We omitted two newts from analyses, leaving a total day 1 and day 2 sample of 16 newts. One newt escaped from a container containing $B d$-exposed conspecific cues during non-recording hours after day 1 . Another died in a container with unexposed conspecific cues during recording hours on day 2. An additional newt never entered the aquatic portion of their container on day 1 , leaving the possibility that this newt did not experience Day 1 treatment conditions. Re-analyzing the day 2 data with this newt omitted did not qualitatively change the results (Supplementary Tables 2,3).

Habitat use of the remaining sixteen newts was variable across both experimental days (Figure 1 and Table 1). Neither general conspecific cues nor $B d$-exposed conspecific cues influenced any measures of newt habitat use on the first day (null models performed best in all cases, Table 2). Similarly, newt habitat use on day 2 was not influenced by the aquatic conditions encountered on that day (Table 3). There was, however, indication that the proportion of time that newts spent aquatic on Day 2 depended on the aquatic conditions encountered on day 1 (Table 3). Specifically, newts that encountered water used by $B d$-exposed conspecifics on day 1 spent proportionally less time in aquatic habitat on Day 2 (Figure 1A, effect size $\pm \mathrm{SE}=-0.26 \pm 0.11$ ). The aquatic habitats encountered on Day 1 also factored slightly into the number of habitat transitions that newts made on day 2 (effect size $=-1.90 \pm 0.83$, Table 3 ). Newts tended to make fewer transitions between aquatic and terrestrial habitats on day 2 after encountering water from $B d$ exposed conspecifics on day 1 compared with newts that did not encounter those conditions on day 1 (Figure 1B). The aquatic habitats encountered on day 1 and Day 2 did not influence the time that newts first entered aquatic habitat (Supplementary Table 1) or the average length of stay in aquatic habitat on either day (Tables 2, 3).

\section{DISCUSSION}

Much work has shown that animals make habitat use decisions based on cues of conspecific density and reproductive performance (Danchin et al., 1998; Stamps, 2001; Doligez et al., 2002). Here, we provide evidence that habitat use is also informed by conspecific cues of parasitism. Female newts became more sedentary on land after encountering aquatic habitats previously used by $B d$-exposed conspecifics. Exactly which cues sourced from $B d$-exposed conspecifics drove these responses - those produced by conspecifics, those produced by $B d$ stages infecting them, or infectious stages shed into the 
TABLE 1 | Summary statistics of the measures of newt habitat use.

\begin{tabular}{|c|c|c|c|c|c|c|c|c|}
\hline \multirow[b]{2}{*}{ Response } & \multicolumn{4}{|c|}{ Day 1} & \multicolumn{4}{|c|}{ Day 2} \\
\hline & $\min$ & $\max$ & mean & SE & $\min$ & $\max$ & mean & SE \\
\hline $\begin{array}{l}\text { Time to first entry into } \\
\text { aquatic habitat }\end{array}$ & 1 & 608 & 83 & 41 & 1 & 674 & 129 & 68 \\
\hline $\begin{array}{l}\text { Proportion of time in } \\
\text { aquatic habitat }\end{array}$ & 0.00 & 0.95 & 0.23 & 0.06 & 0.00 & 0.35 & 0.12 & 0.03 \\
\hline $\begin{array}{l}\text { Total number of } \\
\text { habitat transitions }\end{array}$ & 0.00 & 94.00 & 40.06 & 7.73 & 0.00 & 140.00 & 37.75 & 12.40 \\
\hline
\end{tabular}

TABLE 2 | Factors influencing newt habitat use on Day 1.

\begin{tabular}{|c|c|c|c|c|}
\hline Conspecific cues Day 1 & Bd cues Day 1 & df & $\triangle \mathrm{AICc}$ & Weight \\
\hline \multicolumn{5}{|c|}{ Proportion of time in aquatic habitat } \\
\hline & & 2 & 0 & 0.66 \\
\hline & -0.08 & 3 & 2.67 & 0.17 \\
\hline-0.01 & & 3 & 3.06 & 0.14 \\
\hline 0.03 & -0.10 & 4 & 6.26 & 0.03 \\
\hline \multicolumn{5}{|c|}{ Number of habitat transitions } \\
\hline & & 2 & 0.00 & 0.67 \\
\hline \multirow[t]{2}{*}{0.23} & & 3 & 2.88 & 0.16 \\
\hline & -0.14 & 3 & 3.01 & 0.15 \\
\hline 0.3483 & -0.2801 & 4 & 6.28 & 0.03 \\
\hline \multicolumn{5}{|c|}{ Average length of stay in aquatic habitat } \\
\hline & & 2 & 0.00 & 0.68 \\
\hline \multirow[t]{2}{*}{-0.03} & & 3 & 3.07 & 0.15 \\
\hline & 0.00 & 3 & 3.08 & 0.15 \\
\hline-0.04 & 0.02 & 4 & 6.70 & 0.02 \\
\hline
\end{tabular}

Outputs of multi-model inference testing the factors that influence three measures of newt habitat use on the first day of the experiment: the proportion of time individuals spent in aquatic habitat, the number of transitions made between aquatic and terrestrial habitats, and the average length of stay in aquatic habitats before moving back to land. 'Conspecific cues' denotes containers with aquatic habitats that were previously occupied by conspecifics, regardless of their $\mathrm{Bd}$ exposure. 'Bd cues' denotes containers with aquatic habitats that were previously occupied by Bd-exposed conspecifics specifically. Models are listed in order of their Akaike's Information Criteria (A/CC) ranking, with the first listed model being the best performing one. Values listed in the factor columns are the model coefficients. Df $=$ degrees of freedom.

water by conspecifics - remain to be determined. In either case, the responses are evidence that non-visual cues of infection risk sourced from conspecifics can drive newts to alter habitat use. Further, newt increases in terrestrial activity were not immediate, and instead occurred the day after encountering conspecific cues of $B d$, but still well before $B d$ infections had time to fully develop (which takes at least 4 days, Daversa et al., 2018a). These observations suggest that $B d$ can drive newts to avoid aquatic habitats prior to establishing sustained infections.

The female responses to water used by $B \mathrm{~d}$-exposed conspecifics strengthens growing evidence that $B d$ imposes costs to occupying aquatic habitats (Miaud et al., 2016; Daversa et al., 2018a). Further, females reduced aquatic activity more proactively than males did in a similar set of experiments
TABLE 3 | Factors influencing newt habitat use on Day 2.

\begin{tabular}{|c|c|c|c|c|c|c|}
\hline \multicolumn{7}{|c|}{ Proportion of time in aquatic habitat } \\
\hline $\begin{array}{l}\text { Bd cue - } \\
\text { Day } 1\end{array}$ & $\begin{array}{l}\text { Bd cue - } \\
\text { Day } 2\end{array}$ & $\begin{array}{l}\text { Conspecific } \\
\text { cue - Day } 1\end{array}$ & $\begin{array}{l}\text { Conspecific } \\
\text { cue - day } 2\end{array}$ & df & $\triangle \mathrm{AICc}$ & weight \\
\hline-0.26 & & & & 3 & 0.00 & 0.40 \\
\hline \multirow[t]{2}{*}{-0.20} & & -0.13 & & 4 & 1.81 & 0.16 \\
\hline & & -0.22 & & 3 & 2.31 & 0.13 \\
\hline-0.26 & -0.03 & & & 4 & 3.48 & 0.07 \\
\hline \multirow[t]{4}{*}{-0.26} & & & -0.01 & 4 & 3.62 & 0.07 \\
\hline & & & & 2 & 3.97 & 0.06 \\
\hline & 0.02 & -0.22 & & 4 & 5.89 & 0.02 \\
\hline & & -0.22 & -0.01 & 4 & 5.93 & 0.02 \\
\hline
\end{tabular}

\begin{tabular}{|c|c|c|c|c|c|c|}
\hline \multicolumn{7}{|c|}{ Number of habitat transitions } \\
\hline $\begin{array}{l}\text { Bd cue - } \\
\text { Day } 1\end{array}$ & $\begin{array}{l}\text { Bd cue - } \\
\text { Day } 2\end{array}$ & $\begin{array}{l}\text { Conspecific } \\
\text { cue - Day } 1\end{array}$ & $\begin{array}{l}\text { Conspecific } \\
\text { cue - day } 2\end{array}$ & df & $\Delta \mathrm{AlCc}$ & weight \\
\hline \multirow[t]{2}{*}{-1.89} & & & & 3 & 0.00 & 0.38 \\
\hline & & & & 2 & 1.36 & 0.19 \\
\hline \multirow[t]{2}{*}{-1.99} & & & 0.47 & 4 & 3.24 & 0.08 \\
\hline & & -0.83 & & 3 & 3.26 & 0.07 \\
\hline-1.70 & & -0.37 & & 4 & 3.42 & 0.07 \\
\hline \multirow[t]{3}{*}{-1.91} & 0.23 & & & 4 & 3.53 & 0.07 \\
\hline & & & 0.20 & 3 & 4.38 & 0.04 \\
\hline & 0.13 & & & 3 & 4.41 & 0.04 \\
\hline
\end{tabular}

Average length of stay in aquatic habitat

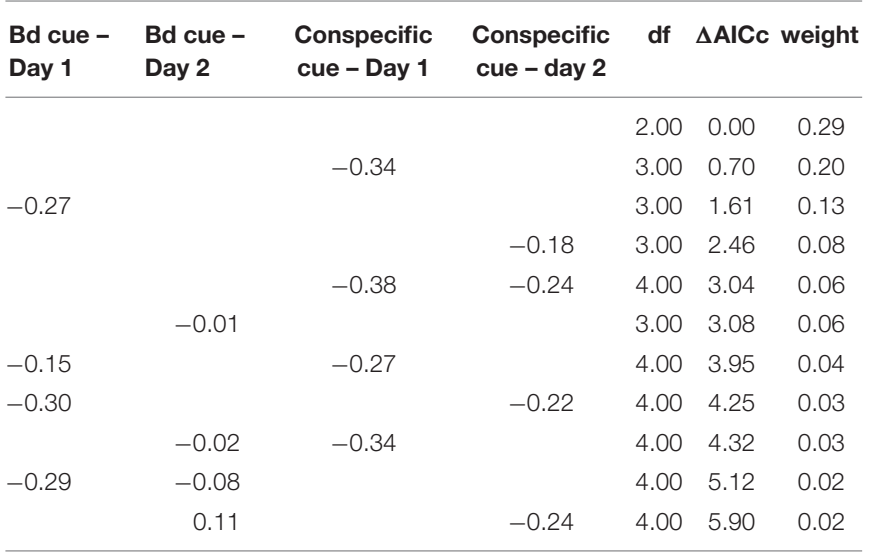

Outputs of multi-model inference testing the factors that influence three measures of newt habitat use on the second day of the experiment: the proportion of time individuals spent in aquatic habitat, the number of transitions made between aquatic and terrestrial habitats, and the average length of stay in aquatic habitats before moving back to land. 'Conspecific cues' denotes containers with aquatic habitats that were previously occupied by conspecifics, regardless of their Bd exposure. 'Bd cues' denotes containers with aquatic habitats that were previously occupied by Bd-exposed conspecifics specifically. Models are listed in order of their Akaike's Information Criteria (AICC) ranking, with the first listed model being the best performing one. Values listed in the factor columns are the model coefficients. Only models within 6 AlCc values of the best performing model are shown (See Supplementary Table 4 for full list). Df= degrees of freedom.

(Daversa et al., 2018a), suggesting $B d$ may impose sex specific costs of aquatic activity. For males, there is a premium on spending time in aquatic habitat because females are the choosy sex in terms of mating. Mating pressures may drive males to take 
more risks in the water before heading for land than females, potentially leading to higher rates of parasitic infection in males (Raffel, 2006).

$B d$-imposed costs of aquatic activity present clear trade-offs with breeding and other fitness-related aquatic activities (e.g., feeding, predator evasion) that may shape newt decision-making. Although we intentionally ran our experiments during late stages of the breeding season, the sustained aquatic activity exhibited by females that did not encounter cues of $B d$ suggests that they still had incentive to use aquatic habitats during later breeding stages. Achieving a mating does not ensure fertility for female alpine newts, and many mate multiple times over the course of a breeding season (Garner and Schmidt, 2003; Hoeck and Garner, 2007). Avoidance of aquatic habitats carrying cues of $B d$ clearly conflicts with these mating patterns and potentially compromises fitness. Alternatively, reduced time aquatic habitats could have resulted from females waiting for males posing reduced infection risk, and this increased selectivity could actually increase fitness. The impact of $B d$ cues on female decision-making may also depend on their infection status, which could not be tested here. Understanding how newts allocate time in aquatic versus terrestrial habitat may be achieved, at least in part, from the perspective of trade-offs between reproduction and parasitism.

Even subtle differences in the timing of newt responses to $B d$ may affect their broader ecological consequences (Daversa et al., 2021). Bd could conceivably drive population declines in newts non-lethally and non-consumptively through costs to fecundity if the female reductions in aquatic activity observed here are sustained for extended periods of time. Epidemiologically, however, newt avoidance of water with conspecific cues of $B d$ should have negative impacts on the parasite because newt terrestrial activity reduces their likelihood of contracting and maintaining infections (Daversa et al., 2018a). If female reductions in aquatic activity prevent infections from developing, then female terrestriality should drive down infection prevalence and spread, similar to how wildlife migration can reduce infection prevalence and spread by allowing animals to "escape" infection (Altizer et al., 2011; Daversa et al., 2017). Expanding our design to field enclosures with multiple discrete aquatic habitats could gain insight into how female avoidance of conspecific cues of $B d$ in water alter how $B d$ persists and spread over the landscape. Tracking animals over longer time periods than we did would also be useful for clarifying how reductions in aquatic activity impact the course of $B d$ infections.

The specific mechanisms driving females to become more terrestrial remain to be determined, though our experiments favor certain hypotheses. Visual cues from conspecifics were clearly not involved because conspecifics were never present during the experiment. We cannot rule out the possibility that newts responded to active $B d$ zoospores shed into the water previously from $B d$-exposed conspecifics, or very early stages of infection from those zoospores. However, the low infection burdens that newts typically acquire (Miaud et al., 2016; Daversa et al., 2018a) suggest that zoospore concentrations in water previously used by $B d$-exposed conspecifics were low. We hypothesize that newt responses were likely elicited by compositional changes in cues emitted by $B d$-exposed conspecifics, such as pheromones, which newts use to communicate for mating, orientation, and likely other activities (Joly and Miaud, 1993; Denoël and Doellen, 2010; Treer et al., 2013). Although the potential for $B d$ exposure to influence the composition of chemical cues of amphibians has not been tested previously, support for our hypothesis comes from evidence for a chemosensory impact in other aquatic systems (Poulin et al., 1999; Stephenson et al., 2015; Behringer et al., 2018). Experimental data on fish, for example, indicate that individuals avoid conspecifics (Stephenson et al., 2018) and exhibit defensive movements (Poulin et al., 1999) in response to infected conspecifics but not to the parasites themselves. Alternatively, females may have responded to cues of stress left by $B d$-exposed conspecifics (Gabor et al., 2013; Auld et al., 2014; Nadler et al., 2020). These putative mechanisms could be tested by sampling both aquatic habitats and conspecifics for pheromones, corticosterone, and $B d$ zoospores. Adding treatments to our design that, for example, expose newts directly to $B d$ zoospores in water or to cues from conspecifics facing with other forms of stress (e.g., predator-induced) could disentangle the specific mechanisms driving newt responses to water previously used by $B d$-exposed conspecifics.

Regardless of the mechanisms involved, our findings build on the evidence base that parasites play a key role in shaping amphibian habitat use (Kriger and Hero, 2007; Raffel et al., 2015; Daversa et al., 2018a,b). This argument is not new. Anecdotes of amphibians going terrestrial in response to parasites, such as leeches, date back to the 1970's (Gill, 1978), and these anecdotes have since been backed by systematic surveillance (Raffel, 2006). This collective body of work leads to an interesting prediction that terrestrial activity may be a general adaptive response for minimizing infection risk. Future empirical work on $B d$ may benefit from more emphasis toward infection dynamics during terrestrial phases of amphibians, which to date remain less studied than infection dynamics in fully aquatic habitats. More broadly, this work points to non-visual cues as a source of information driving parasite avoidance.

\section{DATA AVAILABILITY STATEMENT}

The original contributions presented in the study are included in the article/Supplementary Material, further inquiries can be directed to the corresponding author.

\section{ETHICS STATEMENT}

The animal study was reviewed and approved by the Consejería de Medio Ambiente, Madrid, Spain.

\section{AUTHOR CONTRIBUTIONS}

DD formulated the hypothesis and wrote the initial manuscript, which was revised according to the comments of AM, TG, $\mathrm{HB}$, and JB. DD, JB, PL, and $\mathrm{HB}$ designed the experiments. $\mathrm{DD}$ and $\mathrm{HB}$ executed the experiments. DD and AM performed 
the data analysis. All authors contributed to the article and approved the submitted version.

\section{FUNDING}

This work was funded by Research England, the Cambridge Trusts, and a grant from the Natural Environment Research Council UK (NE/N009800/1).

\section{ACKNOWLEDGMENTS}

We thank the Cambridge Trusts, Research England, and NERC for funding this study, the personnel of Guadarrama

\section{REFERENCES}

Altizer, S., Bartel, R., and Han, B. A. (2011). Animal migration and infectious disease risk. Science 331, 296-302. doi: 10.1126/science.1194694

Anderson, R. M., and May, R. M. (1981). The population dynamics of microparasites and their invertebrate hosts. Philos. Trans. R. Soc. Lond. B Biol. Sci. 291, 452-491.

Arnold, T. W. (2010). Uninformative parameters and model selection using Akaike's information criterion. J. Wildl. Manage. 74, 1175-1178. doi: 10.2193/ 2009-367

Auld, S. K. J. R., Hall, S. R., Housley Ochs, J., Sebastian, M., and Duffy, M. A. (2014). Predators and patterns of within-host growth can mediate both among-host competition and evolution of transmission potential of parasites. Am. Nat. 184, S77-S90. doi: 10.1086/676927

Bartoñ, K. (2019). MuMIn: Multi-Model Inference. Available online at: https:// CRAN.R-project.org/package=MuMIn (accessed 12, September 2020).

Behringer, D. C., Karvonen, A., and Bojko, J. (2018). Parasite avoidance behaviours in aquatic environments. Philos. Trans. R. Soc. Lond. B Biol. Sci. 373:20170202. doi: 10.1098/rstb.2017.0202

Bosch, J., Martínez-Solano, I., and García-París, M. (2001). Evidence of a chytrid fungus infection involved in the decline of the common midwife toad (Alytes obstetricans) in protected areas of central Spain. Biol. Conserv. 97, 331-337. doi: 10.1016/s0006-3207(00)00132-4

Bosch, J., Fernández-Beaskoetxea, S., Garner, T. W. J., and Carrascal, L. M. (2018). Long-term monitoring of an amphibian community after a climate change- and infectious disease-driven species extirpation. Glob. Change Biol. 24: 2622-2632. doi: $10.1111 / \mathrm{gcb} .14092$

Boyle, D. G., Boyle, D. B., Olsen, V., Morgan, J. A. T., and Hyatt, A. D. (2004). Rapid quantitative detection of chytridiomycosis (Batrachochytrium dendrobatidis) in amphibian samples using real-time Taqman PCR assay. Dis. Aquat. Organ. 60, 141-148. doi: 10.3354/dao060141

Briggs, C. J., Knapp, R. A., and Vredenburg, V. T. (2010). Enzootic and epizootic dynamics of the chytrid fungal pathogen of amphibians. Proc. Natl. Acad. Sci. U. S. A. 107, 9695-9700. doi: 10.1073/pnas.0912886107

Buck, J. C., and Ripple, W. J. (2017). Infectious agents trigger trophic cascades. Trends Ecol. Evol. 32, 681-694. doi: 10.1016/j.tree.2017.06.009

Buck, J. C., Weinstein, S. B., and Young, H. S. (2018). Ecological and evolutionary consequences of parasite avoidance. Trends Ecol. Evol. 33, 619-632. doi: 10. 1016/j.tree.2018.05.001

Burnham, K. P., and Anderson, D. R. (2002). Model Selection and Multimodel Inference: A Practical Information-Theoretic Approach. New York, NY: Springer.

Chivers, D. P., Kiesecker, J. M., Wildy, E. L., Belden, L. K., Kats, L. B., and Blaustein, A. R. (1999). Avoidance response of post-metamorphic anurans to cues of injured conspecifics and predators. J. Herpetol. 33:472-476. doi: 10. 2307/1565645

Danchin, E., Boulinier, T., and Massot, M. (1998). Conspecific reproductive success and breeding habitat selection: implications for the study of coloniality. Ecology 79, 2415-2428. doi: 10.1890/0012-9658(1998)079[2415:crsabh]2.0.co;2 mountain national park for supporting the collection of newts; Jose Martin for arranging space for experimental setups, Matthew C. Fisher for culturing $B d$ isolates; Gloria Lopez for assisting with the construction of experimental containers and the other researchers at "El Ventorrillo" biological station for their general support; and the two reviewers for the helpful comments.

\section{SUPPLEMENTARY MATERIAL}

The Supplementary Material for this article can be found online at: https://www.frontiersin.org/articles/10.3389/fevo.2021. 636099/full\#supplementary-material

Daversa, D. R., Fenton, A., Dell, A. I., Garner, T. W. J., and Manica, A. (2017). Infections on the move: how transient phases of host movement influence disease spread. Proc. Biol. Sci. 284:20171807. doi: 10.1098/rspb.2017. 1807

Daversa, D. R., Hechinger, R. F., Madin, E., Fenton, A., Dell, A. I., Ritchie, E. G., et al. (2021). Broadening the ecology of fear: non-lethal effects arise from diverse responses to predation and parasitism. Proc. R. Soc. B.28820202966. doi: 10.1098/rspb.2020.2966

Daversa, D. R., Manica, A., Bosch, J., Jolles, J. W., and Garner, T. W. J. (2018a). Routine habitat switching alters the likelihood and persistence of infection with a pathogenic parasite. Funct. Ecol. 32, 1262-1270. doi: 10.1111/1365-2435. 13038

Daversa, D. R., Monsalve-Carcaño, C., Carrascal, L. M., and Bosch, J. (2018b). Seasonal migrations, body temperature fluctuations, and infection dynamics in adult amphibians. PeerJ 6:e4698. doi: 10.7717/peerj. 4698

Denoël, M., and Doellen, J. (2010). Displaying in the dark: light-dependent alternative mating tactics in the alpine newt. Behav. Ecol. Sociobiol. 64, 11711177. doi: 10.1007/s00265-010-0933-0

Doligez, B., Danchin, E., and Clobert, J. (2002). Public information and breeding habitat selection in a wild bird population. Science 297, 1168-1170. doi: 10 . $1126 /$ science. 1072838

Fisher, M. C., and Garner, T. W. J. (2020). Chytrid fungi and global amphibian declines. Nat. Rev. Microbiol. doi: 10.1038/s41579-020-0335-x

Folstad, I., Hope, A. M., Karter, A., and Skorping, A. (1994). Sexually selected color in male sticklebacks: a signal of both parasite exposure and parasite resistance? Oikos 69, 511-515. doi: 10.2307/3545863

Gabor, C. R., Fisher, M. C., and Bosch, J. (2013). A non-invasive stress assay shows that tadpole populations infected with Batrachochytrium dendrobatidis have elevated corticosterone levels. PLoS One 8:e56054. doi: 10.1371/journal.pone. 0056054

Garner, T. W., and Schmidt, B. R. (2003). Relatedness, body size and paternity in the alpine newt, Triturus alpestris. Proc. Biol. Sci. 270, 619-624. doi: 10.1098/ rspb.2002.2284

Garner, T. W. J., Garcia, G., Carroll, B., and Fisher, M. C. (2009). Using itraconazole to clear Batrachochytrium dendrobatidis infection, and subsequent depigmentation of Alytes muletensis tadpoles. Dis. Aquat. Organ. 83, 257-260. doi: 10.3354/dao02008

Gill, D. E. (1978). The metapopulation ecology of the red-spotted newt, Notophthalmus viridescens (Rafinesque). Ecol. Monogr. 48, 145-166. doi: 10. 2307/2937297

Hoeck, P. E., and Garner, T. W. J. (2007). Female alpine newts (Triturus alpestris) mate initially with males signalling fertility benefits. Biol. J. Linn. Soc. 91, 483-491. doi: 10.1111/j.1095-8312.2007.00813.x

Hutchings, M. R., Gordon, I. J., Kyriazakis, I., and Jackson, F. (2001). Sheep avoidance of faeces-contaminated patches leads to a trade-off between intake rate of forage and parasitism in subsequent foraging decisions. Anim. Behav. 62, 955-964. doi: 10.1006/anbe.2001.1837 
Hyatt, A. D., Boyle, D. G., Olsen, V., Boyle, D. B., Berger, L., Obendorf, D., et al. (2007). Diagnostic assays and sampling protocols for the detection of Batrachochytrium dendrobatidis. Dis. Aquat. Organ. 73, 175-192. doi: 10.3354/ dao073175

Jacobsen, H. P., and Stabell, O. B. (2004). Antipredator behaviour mediated by chemical cues: the role of conspecific alarm signalling and predator labelling in the avoidance response of a marine gastropod. Oikos 104, 43-50. doi: 10.1111/j. 0030- 1299.2004.12369.x

Johnson, J. B., and Omland, K. S. (2004). Model selection in ecology and evolution. Trends Ecol. Evol. 19, 101-108. doi: 10.1016/j.tree.2003.10.013

Joly, P., and Miaud, C. (1993). How does a newt find its pond? The role of chemical cues in migrating newts. Ethol. Ecol. Evol. 5, 447-455.

Kats, L. B., and Dill, L. M. (1998). The scent of death: chemosensory assessment of predation risk by prey animals. Écoscience 5, 361-394. doi: 10.1080/11956860. 1998.11682468

Kavaliers, M., Choleris, E., Ågmo, A., and Pfaff, D. W. (2004). Olfactory-mediated parasite recognition and avoidance: linking genes to behavior. Horm. Behav. 46, 272-283. doi: 10.1016/j.yhbeh.2004.03.005

Kavaliers, M., Colwell, D. D., Braun, W. J., and Choleris, E. (2003). Brief exposure to the odour of a parasitized male alters the subsequent mate odour responses of female mice. Anim. Behav. 65, 59-68. doi: 10.1006/anbe.2002.2043

Kopecky, O., Vojar, J., and Denoël, M. (2010). Movements of alpine newts (Mesotriton alpestris) between small aquatic habitats (ruts) during the breeding season. Amphib. Reptil. 31, 109-116. doi: 10.1163/156853810790457821

Koprivnikar, J., and Penalva, L. (2015). Lesser of two evils? Foraging choices in response to threats of predation and parasitism. PLoS One 10:e116569. doi: 10.1371/journal.pone.0116569

Kriger, K. M., and Hero, J.-M. (2007). The chytrid fungus Batrachochytrium dendrobatidis is non-randomly distributed across amphibian breeding habitats. Divers. Distrib. 13, 781-788. doi: 10.1111/j.1472-4642.2007.00394.x

Kristín, P., and Gvoždík, L. (2014). Aquatic-to-terrestrial habitat shift reduces energy expenditure in newts. J. Exp. Zool. A Ecol. Genet. Physiol. 321, 183-188. doi: 10.1002/jez.1849

Martín, J., and López, P. (2006). Links between male quality, male chemical signals, and female mate choice in Iberian Rock Lizards. Funct. Ecol. 20, 1087-1096. doi: 10.1111/j.1365-2435.2006.01183.x

Miaud, C., Dejean, T., Savard, K., Millery-Vigues, A., Valentini, A., Curt Grand Gaudin, N., et al. (2016). Invasive North American bullfrogs transmit lethal fungus Batrachochytrium dendrobatidis infections to native amphibian host species. Biol. Invasions 18, 2299-2308. doi: 10.1007/s10530-016-1161-y

Mierzejewski, M., Horn, C. J., and Luong, L. T. (2019). Ecology of fear: environment-dependent parasite avoidance among ovipositing drosophila. Parasitology 146, 1564-1570. doi: 10.1017/s0031182019000854

Nadler, L. E., Bengston, E., Eliason, E. J., Hassibi, C., Helland-Riise, S. H., Johansen, I. B., et al. (2020). A brain-infecting parasite impacts host metabolism both during exposure and after infection is established. Funct. Ecol doi: 10.1111/ 1365-2435.13695 n/a.

Piotrowski, J. S., Annis, S. L., and Longcore, J. E. (2004). Physiology of Batrachochytrium dendrobatidis, a chytrid pathogen of amphibians. Mycologia 96, 9-15. doi: $10.2307 / 3761981$
Plenderleith, M., van Oosterhout, C., Robinson, R. L., and Turner, G. F. (2005). Female preference for conspecific males based on olfactory cues in a Lake Malawi cichlid fish. Biol. Lett. 1, 411-414. doi: 10.1098/rsbl.2005.0355

Poulin, R., Marcogliese, D. J., and McLaughlin, J. D. (1999). Skin-penetrating parasites and the release of alarm substances in juvenile rainbow trout. J. Fish Biol. 55, 47-53. doi: 10.1111/j.1095-8649.1999.tb00655.x

Raffel, T. (2006). Causes and Consequences of Seasonal Dynamics in the Parasite Community of Red-Spotted Newts (Notophthalmus viridescens).

Raffel, T. R., Halstead, N. T., McMahon, T. A., Davis, A. K., and Rohr, J. R. (2015). Temperature variability and moisture synergistically interact to exacerbate an epizootic disease. Proc. Biol. Sci. 282:20142039. doi: 10.1098/rspb.2014. 2039

R Core Team (2019). R: A Language and Environment for Statistical Computing. Vienna: R Foundation for Statistical Computing.

Scheele, B. C., Pasmans, F., Skerratt, L. F., Berger, L., Martel, A., Beukema, W., et al. (2019). Amphibian fungal panzootic causes catastrophic and ongoing loss of biodiversity. Science 363, 1459-1463. doi: 10.1126/science.aav0379

Stamps, J. (2001). "Habitat selection by dispersers: integrating proximate and ultimate approaches," in Dispersal, eds J. Clobert., E. Danchin, A. Dhondt, and J. Nichols (Oxford: University of Oxford Press), 230-242.

Stephenson, J. F., Perkins, S. E., and Cable, J. (2018). Transmission risk predicts avoidance of infected conspecifics in Trinidadian guppies. J. Anim. Ecol. 87, 1525-1533. doi: 10.1111/1365-2656.12885

Stephenson, J. F., Van Oosterhout, C., Mohammed, R. S., and Cable, J. (2015). Parasites of Trinidadian guppies: evidence for sex-and age-specific traitmediated indirect effects of predators. Ecology 96, 489-498. doi: 10.1890/140495.1

Therneau, T. M. (2015). A Package for Survival Analysis in R. Available online at: https://CRAN.R-project.org/package=survival (accessed February 4, 2021).

Treer, D., Van Bocxlaer, I., Matthijs, S., Du Four, D., Janssenswillen, S., Willaert, B., et al. (2013). Love is blind: indiscriminate female mating responses to male courtship pheromones in newts (Salamandridae). PLoS One 8:e56538. doi: 10.1371/journal.pone.0056538

Venables, W. N., and Ripley, B. D. (2002). Modern Applied Statistics with S. New York, NY: Springer.

Weddeling, K., Hachtel, M., Sander, U., and Tarkhnishvili, D. (2004). Bias in estimation of newt population size: a field study at five ponds using drift fences, pitfalls and funnel traps. Herpetol. J. 14, 1-8.

Conflict of Interest: The authors declare that the research was conducted in the absence of any commercial or financial relationships that could be construed as a potential conflict of interest.

Copyright (C) 2021 Daversa, Manica, Bintanel Cenis, Lopez, Garner and Bosch. This is an open-access article distributed under the terms of the Creative Commons Attribution License (CC BY). The use, distribution or reproduction in other forums is permitted, provided the original author(s) and the copyright owner(s) are credited and that the original publication in this journal is cited, in accordance with accepted academic practice. No use, distribution or reproduction is permitted which does not comply with these terms. 